Abstract

\title{
Development of Effective Anticancer Drug Candidates against Breast and Colon Cancers ${ }^{\dagger}$
}

\author{
Senem Akkoç ${ }^{1,2, *}$, İlhan Özer İlhan ${ }^{1}$ and Veysel Kayser ${ }^{2}$ \\ 1 Department of Chemistry, Faculty of Sciences, Erciyes University, Kayseri 38039, Turkey; \\ ilhano@erciyes.edu.tr \\ 2 Faculty of Pharmacy, The University of Sydney, Sydney 2006, Australia; veysel.kayser@sydney.edu.au \\ * Correspondence: senemakkoc@erciyes.edu.tr or senem.akkoc@sydney.edu.au; Tel.: +90-352-437-52-62 \\ + Presented at the 2nd International Conference on Natural Products for Cancer Prevention and Therapy, \\ Kayseri, Turkey, 8-11 November 2017.
}

Published: 15 November 2017

\begin{abstract}
Breast and colon cancers are a global health problem and they are responsible for causing a large number of deaths. Both of them rank among the most dangerous types of cancer. DLD-1, MDA-MB-231 and HEK 293T cells were cultured in DMEM medium supplemented with $10 \%$ FBS. The cells were seeded into sterile 96-well plates at a density of $1 \times 10^{3}$ cells/well. Cancerous cells were exposed to synthesized drug candidates at nine different concentrations for $72 \mathrm{~h}$. The normal human cells were exposed to drug candidates in the $0.001-100 \mu \mathrm{M}$ range for $24 \mathrm{~h}$. All the synthesized compounds showed evidence of enhanced cytotoxic activity against tested cell lines. In general, compounds containing aromatic groups showed more cytotoxic activity compared to compounds containing alkyl groups. Furthermore, a few compounds showed roughly more in vitro cytotoxic activity than the well-known chemotherapeutic agent cisplatin. A lot of new compounds as NHC precursors were synthesized and extensively characterized. The anticancer properties of compounds were tested. Our results demonstrate that a few compounds exhibited promising results against cancerous cell lines that can be warranted for further investigation as a potential anticancer agent.
\end{abstract}

Keywords: Benzimidazolium salt; cytotoxic activity; breast cancer; colon cancer; MDA-MB-231; DLD-1; HEK-293T; IncuCyte; confocal image

Acknowledgments: This study was financially supported by TUBITAK (1059B141400496), Erciyes University Research Fund (FYL-2016-6492 and FDK-2014-5091) and The University of Sydney.

(C) 2017 by the authors. Licensee MDPI, Basel, Switzerland. This article is an open access article distributed under the terms and conditions of the Creative Commons Attribution (CC BY) license (http://creativecommons.org/licenses/by/4.0/). 